La especulación es una herramienta que los arquitectos conocemos muy bien. Pero ¿para qué más puede ser útil? Liam Young nos presenta aquí un mundo en el cual el diseño ya no puede centrarse sólo en el ser humano. Así, la especulación ya no sería una herramienta para que los arquitectos diseñen edificios, sino una advertencia para redefinir nuestras propias herramientas.

Palabras clave Especulación Paisaje Crítica Procesos Entrevista

Keywords Speculation Landscape Critique Process Interview
MARCELO LÓPEZ-DINARDI: Cuando empezaste a trabajar con el cine y las tecnologías digitales, ¿era por una suerte de descontento respecto de los límites de la producción arquitectónica, o siempre estuviste interesado en la cultura del videojuego o la producción de imágenes y medios digitales?

LIAM YOUNG: No llegué a esta forma de práctica dentro del cine y la industria del entretenimiento a través de una fascinación particular por esos medios en sí mismos. Siempre me interesaron los temas de arquitectura y urbanos, pero parecía que estábamos entrando en un período en el que las formas tradicionales de práctica arquitectónica o urbana ya no eran suficientes a la hora de tratar estos temas.

Estamos en un punto en el cual las fuerzas que dan forma a las ciudades, los espacios y las comunidades culturales que existen dentro de ellos se encuentran fuera de aquello sobre lo cual los arquitectos operarían normalmente. Todas las condiciones que efectivamente dan forma a las ciudades de hoy - redes, sistemas planetarios, inteligencia artificial a escala urbana, fuerzas económicas, tecnologías móviles - existen fuera de los lenguajes de representación tradicionales con los que normalmente opera la arquitectura. Por lo tanto, mi trabajo fue evolucionando hacia formas de narrativa, la ficción y el cine simplemente como una manera de intentar mantenerme a tono con las fuerzas que están moldeando las ciudades.

Cuando trabajaba para Zaha Hadid descubrí que la forma de relacionarnos con las ciudades a través de la construcción de edificios como objetos escul- 
LIAM YOUNG

scI-Arc, Los Angeles, CA, USA

En conversación con / In conversation with

MARCELO LÓPEZ-DINARDI

Department of Architecture

Texas A\&M University, College Station, TX, USA

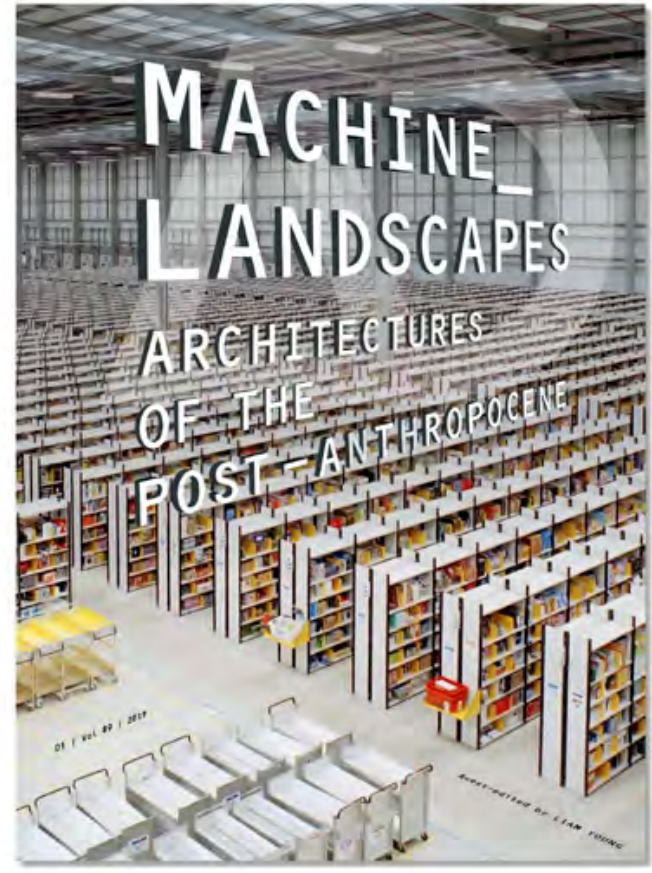

1 Young, Liam (Guest editor). "Special issue: Machine Landscapes: Architectures of the Post Anthropocene". Architectural Design (London) Vol. 89, Issue I (January/ February, 2019). Portada / Cover

MLD: Siguiendo con esa idea, te autodefines como un 'arquitecto especulativo' y sabemos que la especulación es algo que todo arquitecto hace al anticipar e imaginar cosas de antemano. También sabemos que la especulación es una de las principales herramientas de mercado financiero. La especulación implica asumir riesgos. ¿Cuál de estas ideas de especulación es productiva para ti?

LY: Generalmente pensamos la especulación como una forma de asumir riesgos, pero las distintas crisis planetarias a largo plazo han escalado hasta un punto tal en el que ahora el riesgo real está en no especular. Soy alguien que cuenta historias sobre las implicancias arquitectónicas y urbanas de las nuevas tecnologías a escala global, y estas tecnologías y fuerzas llegan más rápido que nuestra capacidad cultural para entender qué pueden significar y cuáles podrían ser sus consecuencias. Entonces la especulación se convierte en una herramienta necesaria y fundamental para vincularnos con estas tecnologías de forma crítica. Tenemos que anticipar e imaginar cuáles podrían ser sus consecuencias de manera tal de prepararnos para una transición que, de cierta manera, ya está entre nosotros. Entonces, es la falta de especulación lo que realmente ha creado muchos de los problemas en los que estamos 


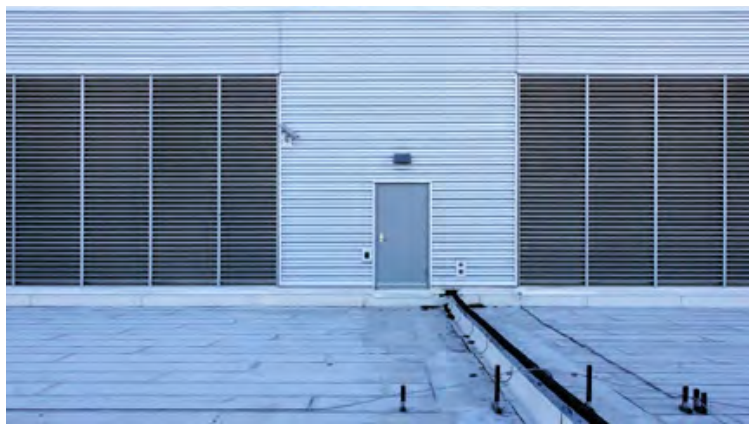

2 A Facebook data center

(c) Liam Young

metidos. La especulación consiste en imaginar lo que podría suceder no para predecir lo que podría haber sucedido y capitalizarlo, sino con la esperanza de que podríamos cambiar nuestras acciones en el presente. O ponemos en marcha prácticas para asegurarnos de que la especulación no se haga realidad o diseñamos las condiciones para que un futuro productivo pueda convertirse en realidad. La especulación es la creación de prototipos de un rango de posibilidades para que podamos alcanzar un cierto entendimiento acerca de dónde queremos ir. Por lo tanto, estamos en un punto donde el futuro es realmente un proyecto y donde la especulación no es un fondo de riesgo, no es una herramienta de modelación financiera, sino una forma necesaria de relacionarse con un presente que se está moviendo demasiado rápido como para que los modos tradicionales de operar sean relevantes o útiles. Muchas de las condiciones que enfrentamos las entiendo como 'tecnologías preculturales', porque llegan más rápido de lo que puede evolucionar nuestra comprensión cultural e ideológica sobre ellas. Son tecnologías previas a las ideologías. La especulación es una forma de modelar lo que podrían ser nuestras respuestas a estas condiciones para que en el presente podamos hacer juicios y tomar decisiones más informadas. El mayor malentendido respecto de la especulación es que trabaja con el futuro. La especulación es en realidad una manera de mirar el presente y ayudarnos a tomar decisiones mejor informadas.

MLD: Al ver tu trabajo y leer algunos de tus escritos, hay mucha discusión sobre lo posthumano, el Antropoceno y el Postantropoceno debido a que estas tecnologías están omitiendo lo humano. Pero al ver tu trabajo en el cine creo que hay algo que es aún más claro: a pesar de que estos edificios - los data centers y ese tipo de infraestructuras - no están necesariamente destinados a ser habitados por seres humanos, igual están vinculados a nosotros. Somos los usuarios-finales que apretamos un botón para que se prenda una cierta luz. ¿Hasta qué punto el ser humano como entidad física permanece o participa de esto? Porque está claro que todavía consideras al cuerpo humano en tus narrativas, ¿no? Los amantes que intercambian mensajes a través de los drones en 
las London Towers en tu película In the robot skies: $a$ drone love story están ahí. ¿Cómo entiendes lo humano como cuerpo - no sólo la condición humana - dentro de estas tecnologías?

LY: Trato de evitar la expresión 'posthumano' porque para la ciencia ficción y la especulación viene demasiado cargado. Lo posthumano todavía privilegia al ser humano como centro de todo; se lo asocia con cosas como cuerpos aumentados, cyborgs, subir tu cerebro a la nube, todas cosas que todavía privilegian al ser humano como el centro de la tecnología. Me interesa más una condición que se describe mejor como lo 'extrahumano', algo que está fuera o más allá de lo humano. Los productos espaciales del mundo 'extrahumano' son lo que denomino 'paisajes de máquinas' [machine landscapes]. Cosas como puertos autónomos, data centers, depósitos logísticos, fábricas electrónicas, etc., constituyen una forma de 'arquitectura sin personas' y existen totalmente independiente o indiferentes de nosotros. Irónicamente, estos paisajes de máquinas son los lugares más críticos de nuestro mundo, pero están completamente vacíos de seres humanos. Por ejemplo, el data center es el espacio cultural y la tipología más representativa de nuestra generación, pero es una condición espacial que no está diseñada para nosotros, no está organizado en torno a la poética de la habitación o a nuestra propia comodidad, es una arquitectura como un vector para el enfriamiento del aire a la temperatura que necesita un disco duro. Cuando nuestra historia colectiva es digital, este es nuestro paisaje cultural; pero a diferencia de la catedral, la biblioteca o la galería de arte, no presupone que los sujetos críticos que participan en ella sean cuerpos físicos que transiten por el espacio. En los paisajes de máquinas, la tradición arquitectónica se desvanece al enfrentarnos a
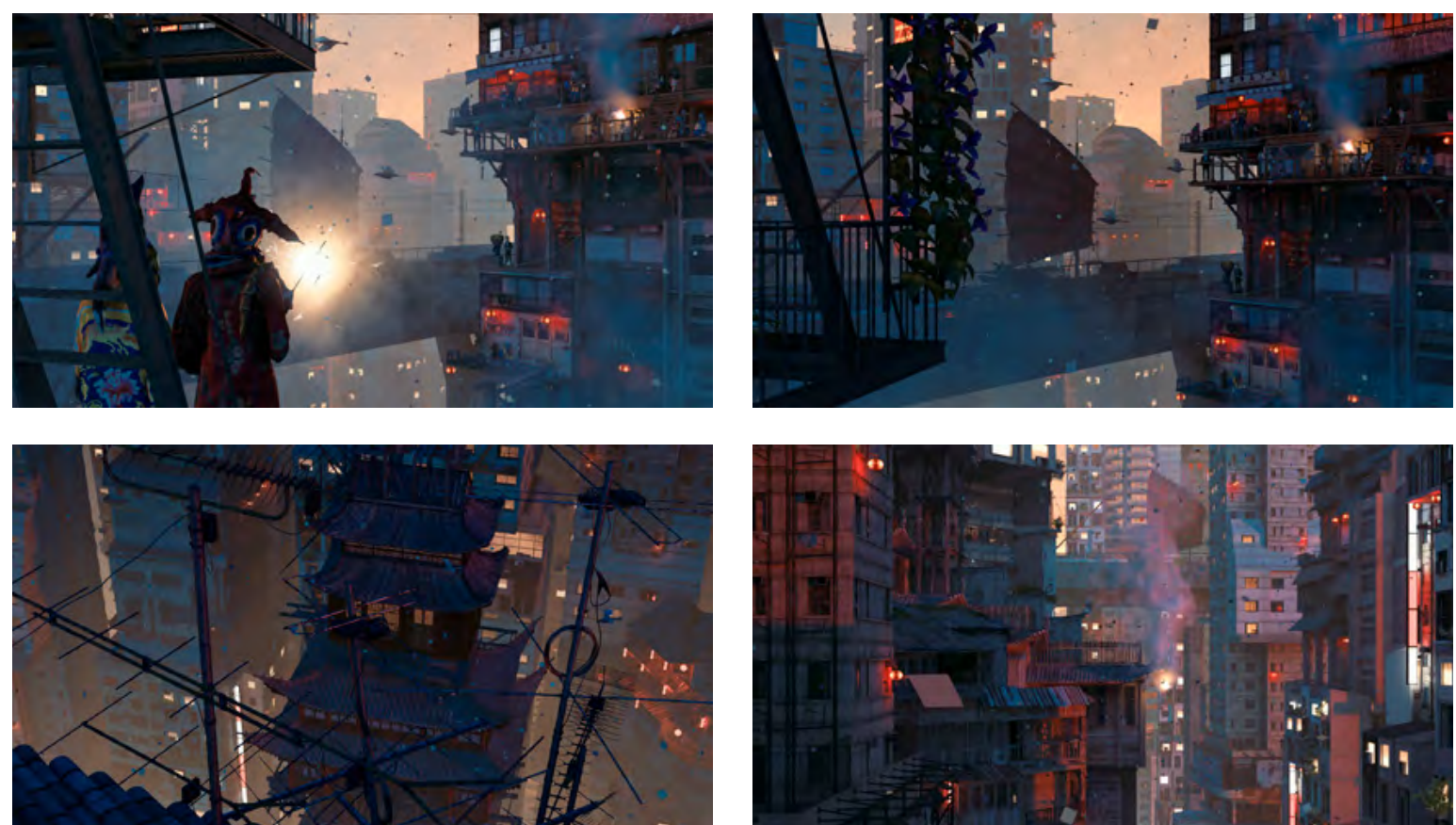


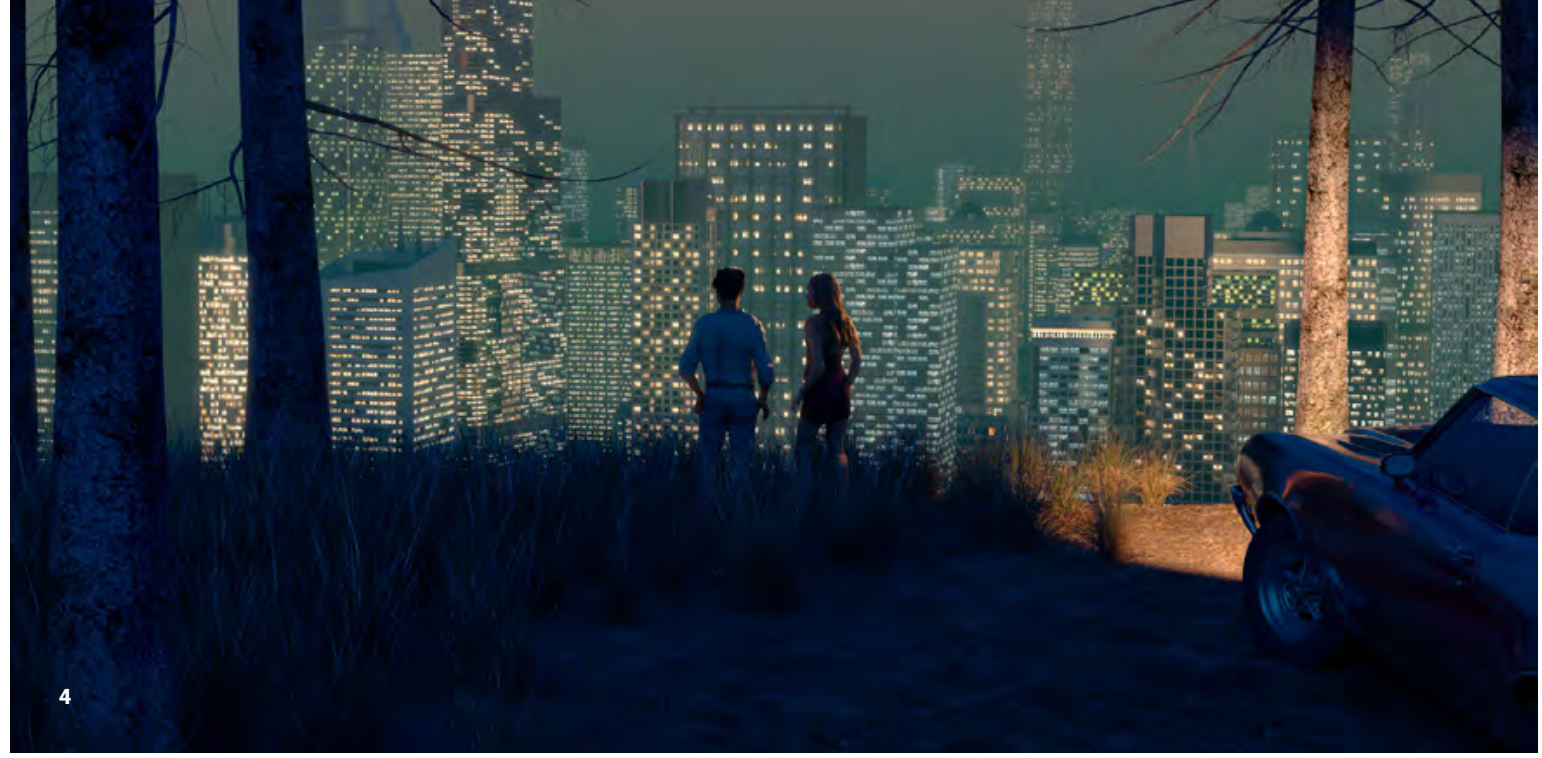

4 Renderlands, 2017 (c) Liam Young condiciones totalmente ajenas al cuerpo humano. El lenguaje de la arquitectura, las proporciones antropomórficas, el manual de dimensiones, las normas de construcción y todas las formas que han sido fundamentales para la tradición de la práctica arquitectónica son totalmente irrelevantes y debemos empezar a desarrollar nuevos lenguajes para lo que podrían ser estos espacios. Mi interés por los paisajes de máquinas es que muestran el final de lo que normalmente denominamos diseño enfocado en el ser humano o en el usuario. Normalmente, esa es una frase que se considera en términos de planificación urbana como la solución para las ciudades. Las imágenes asociadas al diseño enfocado en el ser humano son veredas pavimentadas, hileras de árboles, bulevares, ciudades transitables, pero en realidad el diseño enfocado en el ser humano es fundamental para la crisis en la que estamos hoy. Hemos estado diseñando el planeta a la medida de nuestros propios deseos y comodidades a lo largo de toda nuestra historia. Estoy interesado en lo que significa enfrentarnos a algo así como el diseño centrado en el disco duro, el diseño centrado en la atmósfera, el diseño centrado en la garza americana, el diseño centrado en los humedales o el diseño centrado en el vehículo autónomo. Creo que si vamos a abordar el mundo de una manera significativa y compleja, y si vamos a poder sostenernos a nosotros mismos en un futuro, necesitamos desplazar al cuerpo - al cuerpo humano - como centro de todo lo que nos interesa y todo lo que proyectamos.

MLD: Discutías la relevancia de lo 'posthumano' y cómo nos enfrentamos a ello para generar imaginarios de proyectos no centrados en el ser humano. Siguiendo ese punto, y si pensamos en tus narrativas, creo que tu trabajo es extremadamente antropológico pues cuenta historias sobre cosas hechas por humanos; Pero uno de los aspectos que tendemos a omitir es el problema del trabajo humano y me gustaría saber tu 
«En los paisajes de máquinas, la tradición

arquitectónica se desvanece al enfrentarnos

a condiciones totalmente ajenas al cuerpo

humano. El lenguaje de la arquitectura, las

proporciones antropomórficas, el manual de

dimensiones, las normas de construcción y

todas las formas que han sido

fundamentales para la tradición de la

práctica arquitectónica son totalmente

irrelevantes y debemos empezar a

desarrollar nuevos lenguajes para lo que

podrían ser estos espacios."

opinión al respecto. Los edificios todavía necesitan ser construidos y mantenidos; hay algo importante en relación al trabajo humano en este punto. ¿Cuál es tu reflexión sobre el trabajo humano en la discusión de estos paisajes de máquinas?

LY: En gran parte de los paisajes de máquinas que hemos revisado los seres humanos son una pequeña parte del proceso, pero se los trata como agentes contaminantes dentro de un sistema. En realidad, los seres humanos no sólo son ajenos a las necesidades de los paisajes de máquinas, sino que en la mayoría de los casos estos requieren de nuestra ausencia. En realidad, somos cuerpos extraños a los paisajes de máquinas, agentes externos que deben ser administrados y controlados al punto de que nos comportemos de manera tan predecible como una máquina. Estamos optimizados a tal punto que el cuerpo humano es sólo un componente dentro de los paisajes de máquinas y no se nos permite ningún tipo de agencia. Los cuerpos se calculan y controlan tanto como las máquinas con las que ellos mismos trabajan. Por tanto, creo que la cuestión del trabajo no es tan sencilla como cree mucha gente en los medios de comunicación tradicionales, donde se habla de máquinas que sencillamente reemplazan a los seres humanos. Lo que estamos viendo es que las máquinas trabajan en colaboración con los seres humanos, donde somos sólo un componente dentro de un robot a escala planetaria que está produciendo nuestro mundo. Estuve hace poco en una pequeña ciudad en los montes Urales al norte de Rusia visitando un cultivo indoor de pepinos. Detrás de paredes de doble vidrio sellado, los cultivos son administrados por sistemas de control de inteligencia artificial, con ciclos solares ingenierilmente acortados para acelerar el proceso de crecimiento. Los seres humanos tienen prohibido el acceso a estos espacios agrícolas, son lugares que llamamos 'zonas de exclusión humana'. Los trabajadores de la granja están restringidos a estrechos pasillos entre los campos sellados, que observan detrás del vidrio. Estamos aislados

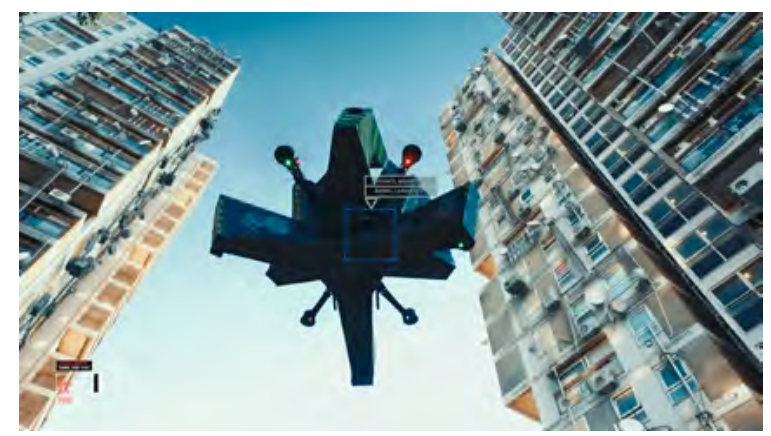

5 In the Robot Skies, 2016

(c) Liam Young 

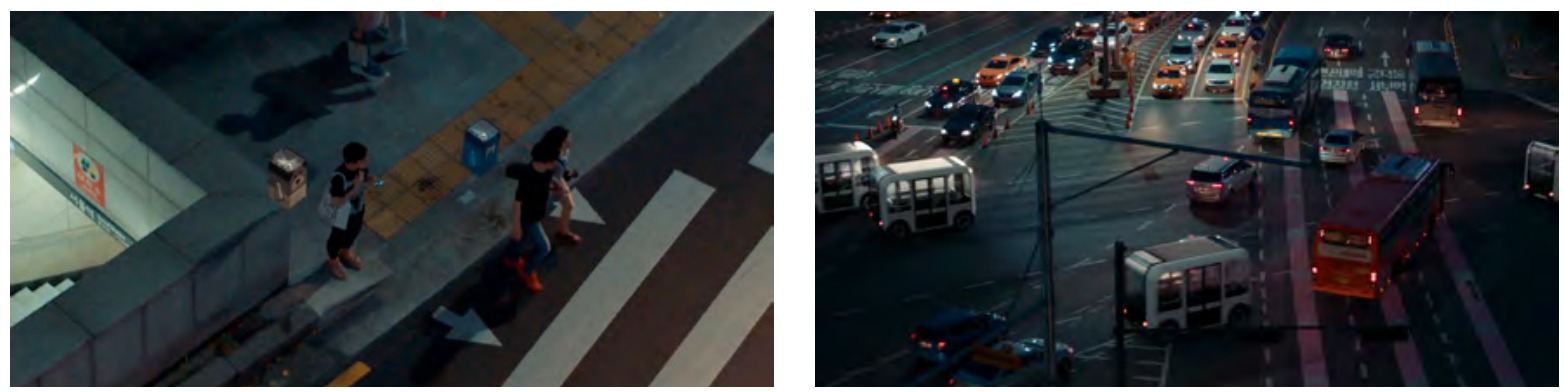

6 Seoul City Machine, 2018 (c) Liam Young

por miedo a que nuestros cuerpos transporten contaminantes o que nuestra respiración o temperatura alteren el sistema. El cuerpo es un agente extraño dentro de estos espacios de producción. Este tipo de zonas de exclusión humana están en todas partes, son realmente los paisajes críticos fundamentales de nuestra era.

Mientras estaba con nuestro taller de investigación Unknown Fields viajando en un barco de carga a través de los puertos de Asia vimos otro ejemplo de esta condición de trabajo mecánico. Gran parte de la flota naviera mundial está controlada y manejada por algoritmos desde oficinas en lugares como Copenhague, donde se encuentra MAERsk, la compañía naviera más grande del mundo. Todavía existe una tripulación que mantiene el barco, pero en la práctica ya no es necesario que estén ahí si muchas de las decisiones que antes tomaba un capitán son gestionadas y controladas por operadores remotos. Nos entusiasma la idea de drones que repartan pizzas o paquetes de Amazon, pero ya existe una enorme flota de miles de barcos no tripulados que reparten el 90\% de todo lo que tenemos. El capitán y la tripulación sólo están ahí cuidando el timón en caso de que algo salga mal o por razones legales, porque aún tenemos que desarrollar la infraestructura legal para gestionar un océano lleno de megabarcos no tripulados. Al final, quizás las últimas personas que queden en pie en estos paisajes de máquinas sean quienes que estén ahí solo por razones legales, donde nuestro único valor sea nuestra presencia física literal.

MLD: Parece crítico, porque esta condición habla de algo a lo que me he referido como el desmembramiento del cuerpo, como una especie de ruptura de nuestra integridad como animales sensoriales y experienciales, y para mí esto es algo que se vincula a tu trabajo en relación a los medios de comunicación. Pareciera que hay una fuerte división, especialmente en nuestra área, entre el grupo que apela a la experiencia sensorial versus los cuerpos-mediatizados que viven en un mundo nervioso-tecnológico. En la introducción a su libro The medium is the message, Marshal McLuhan explica esta idea cuando afirma que «las consecuencias personales y sociales de cualquier medio - es decir, de cualquier extensión de nosotros mismos - resultan de la nueva escala que se introduce en nuestros temas a partir de cada 

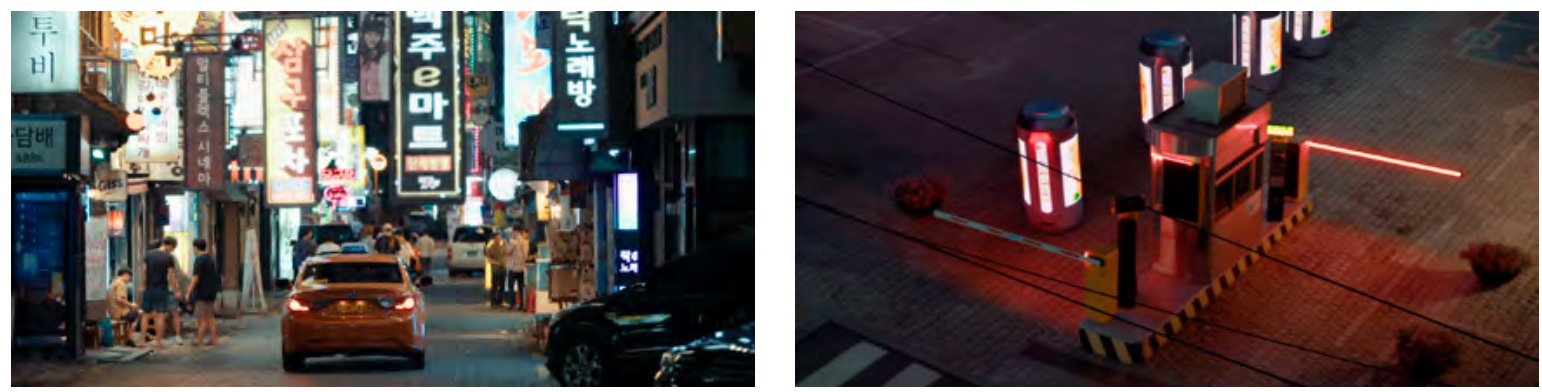

extensión de nosotros mismos, o por cualquier nueva tecnología» (McLuhan, 1964) y tú señalas que debemos comprometernos a una escala global, que debemos trabajar a escala planetaria - y te apoyas por supuesto en el trabajo de Benjamin Bratton con la noción de 'stack' [apilamiento] y el impacto a escala planetaria de la tecnología. ¿Estamos diseñando nuestra propia extensión hasta un punto en el que nos fragmentamos y dejamos de existir como grupo social? Señalo esto principalmente en relación a la democracia. Antes decías que te interesaban los problemas urbanos y los ciudadanos (o las personas en una ciudad), y pareciera que ahora el 'ciudadano' está transformándose en el 'usuario final'. El usuario final es sólo bits o números, mientras que el ciudadano era esta persona que necesitaba aparecer en público, en la ciudad. Entonces, ¿cómo vemos esto en términos de nuestro rol como un colectivo de cuerpos sociales? Si nos desmembramos, ¿desmembramos también la democracia? Tal vez debamos repensar los sistemas políticos al integrar las tecnologías digitales como representativas de nosotros mismos.

LY: Sí y ahora estoy ampliando los temas de Machine Landscapes en un nuevo libro para Strelka Press titulado Architecture Without People. La última línea de la introducción es que el comienzo de los machine landscapes es el fin del diseño centrado en el hombre y señala la necesidad de un diseño centrado en el planeta. Entonces, creo que cuando hablamos de lo humano hablamos de un problema de jerarquía. Nos hemos colocado siempre en la parte superior del diagrama, pero ahora nos vemos enredados en un conjunto más complejo de relaciones planetarias. Ese es el cambio de enfoque que me interesa. Lo que estas tecnologías digitales han hecho es erosionar la relevancia del estado-nación y la red ha creado una condición postgeográfica, post-espacial. Necesitamos comenzar a explorar lo que significa ser ciudadanos de la red, agentes en el espacio digital en lugar de veteranos de una geografía particular, hoy desaparecida. Este es un tema central que apunta a la reimaginación de la propia naturaleza de lo que realmente podría hacer un arquitecto. ¿Cómo operamos sobre una ciudad que ya no se define como un único punto en un mapa y que ya no se entiende como una colección de objetos físicos en los que vive la gente? ¿Cómo servimos a una 

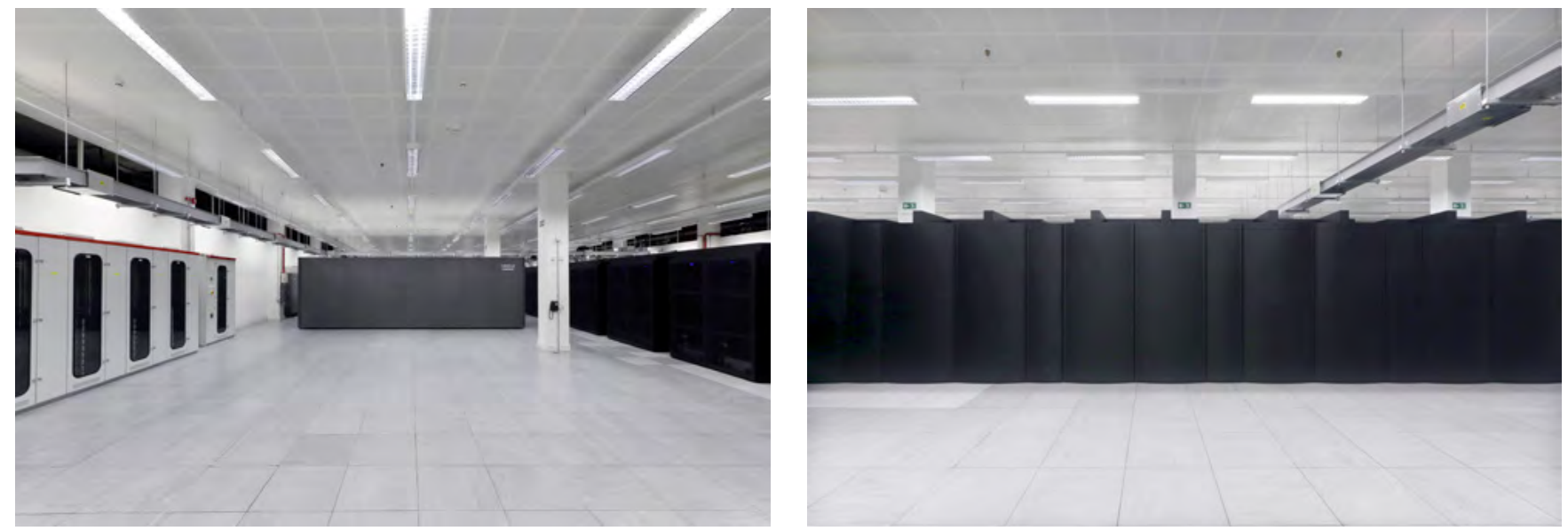

7 Supercomputer. Met Office's Cray xc 40 .

Exeter, UK.

(c) Liam Young ciudad que es en realidad una población atomizada de residentes electrónicos o una serie de protocolos web o direcciones IP? La administración de estas condiciones se basa ahora en plataformas y no en sistemas centralizados de poder. Este tipo de plataforma habla de nuevas formas de gobierno y sugiere nuevos roles que el cuerpo físico podría asumir. Quizás esa sea una manera de abordar tu idea de cuerpos desmembrados donde todos estamos fracturados y distribuidos a lo largo de un territorio en red. Creo que es importante explorar lo que significa diseñar espacios $\mathrm{y}$ arquitecturas que alberguen un cuerpo a escala planetaria y no a escala del Modulor de Le Corbusier o el manual de dimensiones.

MLD: Esta noción de ciudadanos de una red es muy interesante. En relación al tema de la jerarquía, creo que es la herencia de Europa de la cultura occidental: desde el Renacimiento tenemos la idea de que somos el centro y que controlamos todo; y la tecnología siempre ha estado ahí, a nuestro lado. Pero es interesante porque este tema de la jerarquía aparece como pregunta con la idea del ciudadano de una red. Porque dado que estas redes son en gran medida privadas, de alguna manera estamos sujetos a estas redes de las que podemos beneficiarnos, pero a la vez tenemos un grado mínimo de control y agencia sobre ellas. Ha habido casos interesantes con versiones más básicas o anteriores de la tecnología (si pensamos en la Primavera Árabe, por ejemplo), donde la tecnología ayudó a reconfigurar un grupo social en lugar de desmembrarlo. ¿Cómo nos relacionamos con una red que es fundamentalmente privada? ¿Hay alguna manera de pensar esta red que no dependa necesariamente de cinco compañías en el mundo?

LY: Una forma más apropiada de describirlo es que en realidad somos clientes de la red, clientes-ciudadanos. Y a su vez, esto sugiere que ahora somos clientes de la ciudad, como opuestos a los ciudadanos de una ciudad. Estas redes son propiedad de y son operadas por unos pocos grandes grupos. Y hemos llegado a este punto porque muchas de las tecnologías que 
generaron estas condiciones fueron desarrolladas por y para entidades privadas que lo hacen en nombre de accionistas, no en nombre de un público con derecho a voto. Entonces, los sistemas de poder que normalmente resultarían del voto democrático están ahora siendo subcontratados a entidades privadas. Ahora, cuando hablamos de los ciudadanos de la ciudad en realidad estamos hablando de los usuarios de la ciudad y el diseño centrado en el ser humano es una forma más amigable de describir el diseño centrado en el cliente. Las cosas están optimizadas para nuestro beneficio por una cuestión comercial y no por responsabilidad cívica. Necesitamos entender que diseñar el gobierno de las redes es también el mecanismo a través del cual podemos crear nuevas formas de espacios cívicos. Y hay un gran potencial en hacerlo; ya estamos utilizando la red para hacer cosas realmente interesantes. Estamos siendo testigos del surgimiento de lo que podríamos describir como (hashtag) '\#activism' o acciones cívicas posibilitadas por Facebook. Eventos como la marcha de las mujeres o las protestas globales por el cambio climático son acumulaciones de cuerpos humanos a escalas nunca antes vistas. Hemos sido testigos de la reunión más grande de seres humanos en un mismo lugar de toda nuestra historia y se organizó a través de la red. En los comienzos de Internet, la red era vista como algo que podía separarnos, donde simplemente nos quedábamos en nuestras casas teletrabajando y transmitiendo contenido vía streaming. Ahora está siendo entendida como un andamiaje para la acción colectiva a escalas que podrían tener un significado real. Y eso es apasionante, ver que han surgido nuevas estructuras de acción, ya sea a través de la cooptación de plataformas privadas o de la creación de nuevas plataformas. Por lo tanto, estos son precedentes interesantes, pero para que todo esto tenga consecuencias significativas para la gente común y no sólo para los miembros de una élite, se necesita una reconfiguración sustancial de las condiciones de acceso y privacidad. Se necesita un rediseño de estas condiciones hacia lo que podríamos describir como un código público o cívico, en oposición a la propiedad de los ip.

MLD: Es muy interesante, porque tu trabajo aborda estos grandes temas a través de la ficción. Trabajas con la realidad de los datos duros que surgen de estas circunstancias y luego la presentas a través de la ficción para - quizás - hacernos más conscientes de estas condiciones. Y es interesante porque resulta que esta es la historia de la arquitectura. En Machine Landscapes se vislumbra lo que será uno de los proyectos de om A-Rem Koolhaas sobre el campo y cómo estas tecnologías están dando forma a ciertos edificios. Pero me parece que tu trabajo con la ciencia ficción a través del uso de tecnologías digitales, de la industria del cine y el entretenimiento es una continuación de la historia de la arquitectura. Está Marinetti obsesionado con el automóvil y que luego 
"Sería muy raro tener una conversación con un no arquitecto que entienda el proyecto de Le Corbusier para Argel, [...] pero si les preguntas sobre Blade Runner, la mayoría de la gente tendrá algo que decir sobre el futuro de nuestras ciudades. Ese es el poder de la ficción...»

genera todo un movimiento junto a los futuristas basado en estas condiciones. Lo mismo con Le Corbusier y los transatlánticos y los silos y su obsesión por que inspirasen la producción de arquitectura. Pareciera que tu trabajo consiste precisamente en mirar estas mismas cosas, pero no para hacer edificios con formas nuevas. Si Le Corbusier estuviese vivo, estaría mirando las tecnologías digitales y los data centers y descubriría que tal vez lo que tengamos que hacer no sea necesariamente un edificio, que es - me imagino - lo que estás señalando. En tu texto afirmas que en realidad no se trata de la construcción del data center, sino de las implicancias territoriales y sociales que producen estos cambios. Es interesante que menciones esta idea de preparación y anticipación y de cambiar el presente cuando estás generando y trabajando con ciencia ficción. ¿Cómo encaja la ciencia ficción en tu trabajo, cómo funciona? ¿Es el entretenimiento la única forma de involucrar a la gente y no contándoles realidades duras?

LY: El diseño especulativo se ha convertido en un género legítimo en sí mismo. El diseño de productos estuvo siempre muy ligado al deseo de lujo y al capital hasta que personas como Anthony Dunne y Fiona Raby desarrollaron proyectos representativos que mostraban cómo la especulación podía abordar temas urgentes vinculados a la biotecnología o las tecnologías emergentes. Dieron una batalla muy dura por legitimar el diseño de productos más allá del objeto físico que sirviera de apoyo para la discusión. Sin embargo, en varios sentidos, los arquitectos siempre han trabajado a partir de un prototipo que no es físico, porque la naturaleza de la profesión indica que para producir un edificio se requiere una gran cantidad de dinero y la movilización de enormes fuerzas de poder. Para la disciplina siempre ha sido importante especular a través de arquitecturas de papel. Y entiendo que lo que estoy tratando de hacer al cooptar la expresión 'arquitecto especulativo' es legitimar esa forma de actuar no como algo que hacemos para ganar un concurso, algo que hacemos como un trabajo previo al edificio real o entre encargos, sino como proyectos válidos en sí mismos. El éxito de un proyecto especulativo no está en si se concreta o se construye literalmente, sino que opera dentro del mundo en sus propios términos. 
No se lo debería pensar en los mismos términos que lo hicieron los arquitectos en los años 8o, cuando no podían construir y se encerraron a hacer dibujos en instituciones académicas. Eso tampoco es arquitectura especulativa, es sólo mantenerse a flote esperando que la economía cambie. Cuando lanzamos al mundo un proyecto así, debería estar posicionado de forma tal que encuentre tracción y genere cambios en sus propios términos. Ese es el tipo de trabajo que me interesa, y creo que la razón por la cual me interesó cada vez más la ficción y la industria del entretenimiento es porque son formas en las cuales la especulación puede tener peso en el mundo y puede atraer a un público de formas en las que los arquitectos normalmente no lo harían. Sería muy raro tener una conversación con un no arquitecto que entienda el proyecto de Le Corbusier para Argel y no creo que mucha gente tenga algo para decir sobre los dibujos de Micromegas de Libeskind, pero si les preguntas sobre Blade Runner, la mayoría de la gente tendrá algo que decir sobre el futuro de nuestras ciudades. Ese es el poder de la ficción, es un extraordinario medio compartido que trasciende los límites tradicionales que la disciplina arquitectónica nos impone. Si realmente valoramos el trabajo que hacemos, si pensamos que las ideas de las que hablamos en conversaciones como esta son significativas e importantes, entonces es nuestra responsabilidad encontrarle formas a estas conversaciones que las saquen de las típicas conferencias, exposiciones, eventos y revistas que ocupamos. Por eso me interesa la narrativa, porque es una forma de conectar emocionalmente a la gente con las tecnologías que están cambiando esencialmente sus vidas. Quiero que la gente pueda tener una conversación sobre las cosas de las que estamos hablando, en sus casas, en los bares, en las esquinas, porque representan cambios fundamentales en nuestros modos de vida y nuestros sistemas de poder. Es por eso que la ciencia ficción o la práctica cinematográfica tiene un papel realmente importante. El futuro es un verbo, no un sustantivo, es algo a lo que todos damos forma y construimos con nuestras decisiones cotidianas. Entonces, tal vez signifique crear historias para alguien que está trabajando en una de estas grandes compañías de tecnología y está tomando decisiones sobre el desarrollo de una nueva herramienta o una nueva plataforma. Tal vez tome decisiones que estén informadas por alguna de estas conversaciones. Si realmente queremos promover alguno de los cambios sobre los que estamos hablando, será necesario que alguien escriba un código y no lo venda a alguien más por el dinero que pueda obtener, sino que lo haga abierto y accesible; o no aceptar un trabajo realmente bien remunerado en una entidad privada, sino que irse en cambio a trabajar a una municipalidad y escribir softwares para ese municipio sobre gobernanza en las calles, en lugar de trabajar para Google en un campus/ciudad tech en Toronto.

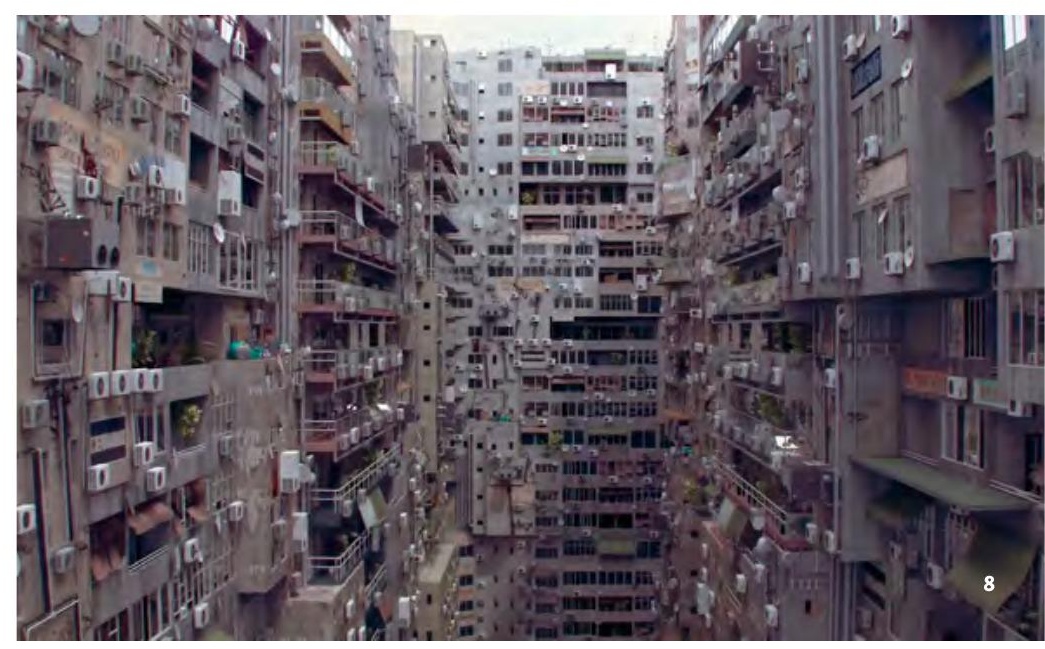

8 Tomorrow's Storeys / Critical fictions on the future of Athens

(c) Liam Young 
Por eso me interesa la especulación. La escala del cambio que necesitamos en relación con la tecnología y la crisis planetaria es tan grande que realmente requiere un cambio cultural. Me interesa lo que eso significa, que operemos y produzcamos objetos e historias culturales, y no edificios como objetos y expresión del capital.

MLD: En la introducción de Machine Landscapes:

Architectures of Post-Anthropocene indicabas que «debemos hacer propio nuestro incómodo lugar en un mundo en el que ya no somos su centro» (Young, 2019). ¿Cuándo crees que ocurrió este cambio? Supongo que te refieres a uno en particular, relacionado principalmente con la tecnología digital y sus implicancias en el espacio, pero tal vez puedas profundizar esa idea de este lugar incómodo y cuándo crees que estábamos realmente enfocados en un diseño centrado en el ser humano, si es que alguna vez lo estuvimos.

LY: De lo que estamos hablando en Machine Landscapes no es de una ruptura dramática a pequeña escala, sino de una condición evolutiva que comenzó con la Revolución Industrial. Los luditas destrozaron las máquinas de tejer y los taxistas de Londres detuvieron el tráfico en protesta por Uber. Ha sido una catástrofe que se arrastra lentamente. Creo que a lo que apelo con un libro así y con el tipo de trabajo que estoy haciendo, el tipo de escritura que estoy produciendo, es a reconocerlo e identificar sus bordes. Cuando nos enfrentamos por primera vez a un nuevo territorio, el acto más importante es mapearlo y nombrarlo. Y en realidad, lo que estoy tratando de hacer es eso, simplemente que identifiquemos y nos enfoquemos en una situación que ha estado a plena vista, pero que hemos hecho todo lo posible por ignorar. Situamos estos paisajes de máquinas en los bordes de la ciudad, los situamos en la periferia, los situamos en países que normalmente no miramos, los habitamos con personas que normalmente no nos importan. Diría que lo que se intentó hacer con el libro Machine Landscapes y con el nuevo libro de Strelka es nombrarlos y mapearlos, describirlos como una situación que ya está aquí. Porque el siguiente paso después de mapear un territorio es decidir si nos mudamos y lo

«Cuando nos enfrentamos por primera vez a un nuevo territorio, el acto más importante es mapearlo y nombrarlo. Y en realidad, lo que estoy tratando de hacer es eso, simplemente que identifiquemos y nos enfoquemos en una situación que ha estado a plena vista, pero que hemos

hecho todo lo posible por ignorar." 
colonizamos. O si lo dejamos tranquilo. Creo que esa es la decisión a la que nos enfrentamos hoy, porque si hemos estado proyectando desde un enfoque centrado en el ser humano, esa ha sido la configuración predeterminada durante un largo tiempo. Y el cambio fundamental no es forzar la entrada a los paisajes de máquinas, derribar la puerta. No creo que sea realmente necesario decir que los data centers son espacios públicos y que deberíamos estar diseñando escenarios donde estemos sentados en los pasillos de los servidores, haciendo un picnic en el data center de Google, ocupándolo como un paisaje. La cuestión no es repetir los errores del pasado, sino reconocer que lo que estos lugares representan es una condición en la que privilegiamos algo más. Creo que aprender de los paisajes de máquinas y los proyectos para la tecnología nos ofrece estrategias para poder diseñar para humedales o para especies de peces. No se trata de diseñar el pez para que podamos capturar más peces, no se trata de diseñar el pez para que crezca más rápido y sea más grande cuando lo comamos, no se trata de diseñar el pez o el arrecife para que podamos verlo cuando vamos de vacaciones y hacemos paseos ecoturísticos, se trata de diseñar los peces porque los peces son tan importantes como nosotros y el mundo los necesita. Entonces, creo que esa es la forma en la que podemos abordar, explorar y aprender de estos paisajes de máquinas. ¿Tiene sentido?

MLD: Sí, absolutamente. También es una buena forma de aclarar cuáles son tus ideas respecto del diseño centrado en el ser humano versus el centrado en lo no humano. Hay por supuesto mucha crítica alrededor del concepto de Antropoceno y Postantropoceno pues evaden la realidad que sufren personas no privilegiadas en estos contextos y no me refiero a máquinas que reemplazan el trabajo humano, sino al crecimiento de la desigualdad o, por ejemplo, el nivel de precariedad en el que empresas como Uber y Lift dejan a los conductores. Hay una condición humana muy profunda en ello, que es el nivel de precariedad de esos trabajadores como seres humanos. Y es una pregunta directa, ¿necesitamos algún tipo de reglamentación para estas tecnologías? Estoy refreaseando algunas de las ideas de Adam Greenfield en Radical Technologies: The Design of Everyday Life (20I7) cuando argumenta que las tecnologías de la información han conquistado nuestra vida cotidiana a través del procesamiento de información. Entonces, ¿necesitamos una normativa para recuperar el control? ¿Es algo que debemos buscar en el marco de estas discusiones?

LY: Sí, algo así. El problema es que las reglamentaciones y soluciones legales para estas cosas se mueven muy lentamente. Por fin estamos llegando a una discusión sobre la normativa de 

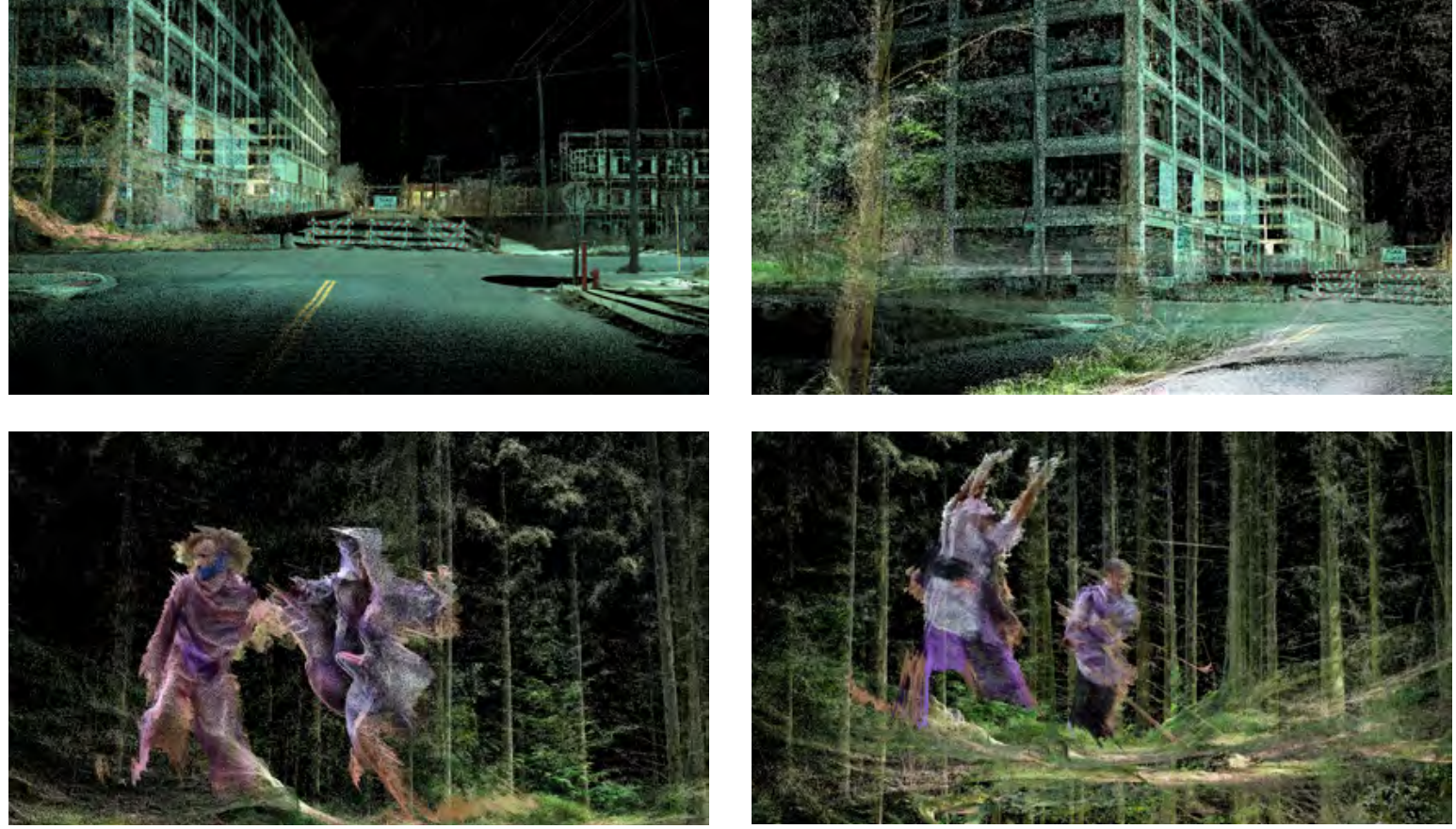

10 Where the City Can't See, 2016

(c) Liam Young
Facebook; hubo audiencias el año pasado en el Senado de Estados Unidos sobre Facebook, tratando de averiguar cómo diablos se volvió susceptible al hackeo ruso y cómo Facebook influenciaba las elecciones, y tal vez tomará otros dos años más para que los resultados de esas audiencias se traduzcan en formas de regulación. Deberíamos haber tenido esa discusión hace io años, cuando comenzó Facebook, porque ahora ya permitió que fuera electo un idiota que está destrozando el mundo. El genio ya está fuera de la botella. ¿Qué significaría regular especulativamente de manera que podamos anticiparnos o imaginarnos y hacer un prototipo para los usos de plataformas como Facebook antes de que se conviertan en realidad? Creo que ese es el tipo de normativa que necesitamos, normativas alineadas con la especulación. Porque en este momento, si piensas en algo como los autos sin conductor, estas cosas ya están llegando. Cambiarán radicalmente las ciudades y cómo operamos dentro de ellas. Y recién ahora la arquitectura y el urbanismo están empezando a pensar qué significa esto: en cada bienal, en cada escuela de arquitectura está el taller o el fondo de investigación o el proyecto de exposición que intenta explorar lo que podría significar el auto sin conductor. Pero ya es demasiado tarde. Las compañías automotrices han invertido miles de millones de dólares en tecnología y no la van a dejar ir. Estas cosas están por venir y debemos apurarnos para descubrir qué significan y cómo las incorporamos de una manera que sea productiva. La única razón por la que todavía no están aquí es porque aún no hemos descubierto a quién demandar cuando atropellen a alguien y lo maten, de lo contrario estarían en todas partes. No es porque no hayamos decidido si pueden o no estar en el espacio público, o la naturaleza de la calle, o 
la formación de la ciudad, esos son problemas a los que nadie les ha dedicado mucho tiempo todavía. ¿Qué significaría crear una forma de práctica regulatoria que nos permitiera tener este tipo de conversaciones antes de que las empresas de tecnología inviertan miles de millones para hacerlos realidad? Creo que esa es una discusión interesante de dar y mi versión de cómo sería está enraizada en formas de ficción especulativa.

MLD: Gracias por tu opinión al respecto. Finalmente, ¿cuáles son los desafíos para las escuelas de arquitectura? ¿Qué deberían estar haciendo las escuelas de arquitectura para ponerse al día con la velocidad del cambio, que es, creo, la presión que estamos sufriendo ahora mismo en todas partes, y cómo nos adaptamos realmente a un cambio que es tan rápido? ¿Qué hacemos en las escuelas de arquitectura para mover realmente una maquinaria? Me refiero a la burocracia de las escuelas, pero también a la maquinaria del conocimiento de nuestro campo, para avanzar y ponerse al día con estas condiciones ¿Podría ser la especulación una de esas respuestas?

LY: La respuesta más amplia es simplemente que debemos entender que existen diferentes tipos de arquitectos que pueden operar en el mundo y debemos educar a los estudiantes para que asuman esos roles, en lugar de educarlos para una profesión que ya no existe. Las escuelas deben seguir siendo relevantes para comprender y capacitar a los estudiantes en nuevas formas de práctica que realmente pueden ayudarnos. La especulación es una forma para ello, pero no la única. ARQ

\section{Bibliografía / Bibliography}

GREENFIELD, Adam. Radical technologies: the design of everyday life.

London; New York: Verso, 2017.

MCLUHAN, Marshall, Understanding media: the extensions of man. New York: McGraw-Hill, I964.
YounG, Liam (Guest editor). «Special issue: Machine Landscapes: Architectures of the Post Anthropocene». Architectural Design (London) Vol. 89, Issue I (January/February, 2019).

\section{Liam Young}

$<$ liam_young@sciarc.edu>

Arquitecto australiano que trabaja entre el diseño, la ficción y el futuro. Es fundador del think tank Tomorrows Thoughts Today, que explora las posibilidades del urbanismo fantástico, especulativo e imaginario. Codirige además la Unknown Fields Division, un equipo de investigación nómade que documenta tendencias emergentes y descubre las débiles señales de posibles futuros. Ha sido reconocido en medios de comunicación tradicionales y especializados en arquitectura, incluyendo la $B B C, N B C$, Wired, Guardian, Time Magazine. Su trabajo ha sido recopilado por instituciones como el Metropolitan Museum of Art y el Victoria and Albert Museum. Ha dictado clases en la Architectural Association y Princeton University y dirige un M.A. in Fiction and Entertainment en scr-Arc. 